\title{
Orthographic and phonological activation in auditory and visual word recognition
}

\author{
MICHAEL K. TANENHAUS and HELEN P. FLANIGAN \\ Center for the Study of Cognitive Processes, Wayne State University, Detroit, Michigan 48202 \\ and \\ MARK S. SEIDENBERG \\ University of Illinois at Urbana-Champaign, Urbana, Illinois 61801
}

\begin{abstract}
A discrete-trials color naming (Stroop) paradigm was used to examine activation along orthographic and phonological dimensions in visual and auditory word recognition. Subjects were presented a prime word, either auditorily or visually, followed $200 \mathrm{msec}$ later by a target word printed in a color. The orthographic and phonological similarity of prime-target pairs varied. Color naming latencies were longer when the primes and targets were orthographically and/or phonologically similar than when they were unrelated. This result obtained for both prime presentation modes. The results suggest that word recognition entails activation of multiple codes and priming of orthographically and phonologically similar words.
\end{abstract}

In languages such as English, words are specified in both spoken (phonological) and written (orthographic) codes. Both codes are related to a single semantic representation, and their use is governed by a single grammar. While initial language experience is spoken, in learning to read, children are taught to map orthographic representations onto existing phonological forms. The literate adult is able to rapidly shift between phonological and orthographic codes for words. Reading aloud, for example, requires orthographic-to-phonological mapping, whereas taking notes requires phonologicalto-orthographic mapping.

These considerations suggest that the orthographic and phonological codes for a word are closely integrated within the mental lexicon. This idea is embedded in Morton's (1969) logogen model and in the Collins and Loftus (1975) spreading activation model. In the logogen model, each word has a corresponding unit (logogen) in memory that contains a representation of its semantic, orthographic, and phonological codes. In the spreading activation model, orthographic and phono-

This paper is partially based on a Wayne State University master's thesis by the second author, directed by the first author. Some of these results were presented at the 51st Meeting of the Midwestern Psychological Association held in Chicago, May 1979. This research was supported by a Wayne State University Research Development Award to the first author. Requests for reprints should be sent to Michael K. Tanenhaus, Psychology Department, Wayne State University, Detroit, Michigan 48202. We thank an anonymous reviewer for pointing out that phonological similarity was confounded in the orthographic condition in Experiment 1 and Linda Sala for providing valuable advice on the manuscript. Mark Seidenberg is now at McGill University. logical information are represented in a single lexical network.

The integrated representation of the sensory codes for words in these models suggests that when a word is recognized, all of its codes become available or "activated." This view predicts that orthographic and phonological codes should become available in both visual and auditory word recognition. There is a great deal of evidence indicating that a sound-based code becomes available in visual word recognition. In a variety of memory tasks, subjects make sound-based confusions to visually presented letters and words (e.g., Baddeley, 1966; R. Conrad, 1964; Wickelgren, 1965.) These effects have usually been attributed to a "recoding" stage impelled by short-term memory limitations (see papers in Kavanagh \& Mattingly, 1972).

The claim that the orthographic code is activated during auditory word recognition is somewhat counterintuitive, but a recent study by Seidenberg and Tanenhaus (1979) found supporting evidence. Their subjects had to detect the word in a short auditorily presented list that rhymed with a cue word. Rhymes that were orthographically similar to the cue (e.g, pietie) were detected faster than words that were orthographically dissimilar (e.g., rye-tie). The effect of cuetarget orthographic similarity obtained whether the cue was presented visually or auditorily. Thus, the orthographic code affected rhyme detection even when the subject saw no stimuli.

Recoding provides a plausible account of phonological effects in visual word recognition, but not of orthographic effects in auditory word recognition. Recoding from visual input to a sound-based code was 
assumed to occur because it made the information easier to maintain in short-term memory. Why, then, should subjects recode from a sound-based code to an orthographic code in the rhyming task? An alternative explanation of both effects is that multiple codes for words are activated automatically (in the sense of Posner \& Snyder, 1975) as a consequence of word recognition. Multiple-code activation occurs in both auditory and visual word recognition, but not necessarily because of memory limitations.

The implications of the Seidenberg and Tanenhaus (1979) study are limited, however, because of their experimental task. Rhyme monitoring has not been widely used in studying word recognition, and it is possible that the task may induce subjects to use strategies that rely upon orthographic information that normally would not be accessed. It is important to determine whether evidence for orthographic code activation in auditory word recognition can be found using a different task. A second drawback of the rhyming task is that it cannot be used to investigate the complementary phenomenon, phonological effects in visual word recognition. The multiple-code interpretation claims that both these effects, which can be termed "cross-modal" code activation, are due to automatic activation of sensory codes. Thus, it is important to observe both effects within the same experimental task.

Priming paradigms, which evaluate the effects of one word on the recognition of a second one, offer a promising vehicle for investigating cross-modal code activation. These paradigms, which have been used extensively to examine semantic effects in word recognition, typically use one of three response measures: word naming, lexical decision, and color naming.

In the word naming paradigm, subjects name a target word as quickly as possible. Faster naming latencies obtain when a prior priming word is associately related to either the target word or a category superordinate of the target, relative to controls in which prime and target are unrelated (Warren, 1972, 1974).

In the widely used lexical decision task, the subject decides whether the target stimulus (which is a nonword or filler trials) is a word or whether both prime and target are words. Lexical decision times are facilitated when the prime is an associate of the target (Meyer \& Schvaneveldt, 1976), a category superordinate of the target (Neely, 1976, 1977), or semantically but not associatively related to the target word (Fischler, 1977).

These facilitation effects due to semantic and associative relatedness have been widely interpreted as automatic; that is, they occur without conscious allocation of attention and do not exhaust limited-capacity central processing resources. Becker and Killion (1977) and Meyer, Schvaneveldt, and Ruddy (1975) obtained evidence supporting this interpretation by demonstrating that the facilitation effect in the lexical decision task occurs at a sensory rather than a decision stage in word recognition.

Particularly compelling evidence that semantic priming effects occur automatically is provided by experiments using a discrete-trials Stroop or color naming paradigm, in which the target word is printed in colored ink and the subject's task is to ignore the word and name the color. Subjects cannot inhibit processing of the target word, which interferes with naming the color, presumably because the articulatory program for the word is activated (Posner \& Snyder, 1975; Warren, 1972). Color naming latencies increase when the target word is preceded by a prime which is an associate or category superordinate of the target word (Warren, 1972, 1974). The logic of this task in the priming paradigm is similar to that of the lexical decision or naming task, except that priming interferes with color naming, whereas it facilitates lexical decisions and word naming. Priming increases the speed of recognition and thus the strength of the target word as a competing response, producing greater color naming interference. The subject is discouraged from encoding the target word because it never provides information that could facilitate color naming. Since the target word nonetheless interferes with color naming, these priming effects are usually attributed to automatic processing (see Posner \& Snyder, 1975). The subject is also unlikely to recall the target words and thus form task-specific processing strategies (Warren, 1972).

Several studies have used priming tasks to investigate orthographic and phonological code activation in word recognition. Meyer, Schvaneveldt, and Ruddy (1974) used the lexical decision task to investigate visually presented word pairs such as "freak-break" and "pouchcouch." Lexical decision times showed facilitation when word pairs were both orthographically and phonologically similar (pouch-couch), whereas they showed interference when the word pairs were orthographically similar but phonologically dissimilar (freak-break). These results suggested that subjects accessed both orthographic and phonological codes in visual word recognition. Shulman, Hornak, and Sanders (1978) replicated this finding, but only in conditions in which the nonword stimuli were nonpronounceable, calling into question whether visual word recognition necessarily involves access to the phonological code. With nonpronounceable nonwords, facilitation rather than interference was obtained with "freak-break" pairs. Shulman et al. argues that Meyer et al.'s (1974) results were due to a strategy induced by the lexical decision task.

C. Conrad (1978) has reported pilot results using a color naming paradigm that suggest that encoding a spoken word leads to activation of an orthographic code. Subjects heard three orthographically similar rhymes followed by a target word that was either orthographically or phonologically similar to the rhymes. Color naming latencies to the target word were longer 
relative to targets that were unrelated to the rhymes. C. Conrad's results suggest that the orthographic effects obtained by Seidenberg and Tanenhaus (1979) are not restricted to the rhyme-monitoring task.

The present studies were conducted to investigate orthographic and phonological code activation in visual and auditory word recognition. Experiment 1 is a replication and extension of C. Conrad (1978) ${ }^{1}$ Priming words were either presented auditorily or visually; targets were always visual and printed in colored ink. Color naming interference was used to diagnose which sensory codes of the prime and target words were activated. With entirely visual presentation of the stimuli, a prime word should facilitate the encoding of a target that is similar in spelling, yielding greater color naming interference compared with controls. If subjects also access the phonological code in visual word recognition, then pairs that are similar only in sound should also show interference compared with controls. Similarly, with auditory primes, targets that are phonologically similar will show increased color naming interference only if subjects access the phonological code for targets. Orthographically similar pairs will show interference only if subjects access the orthographic code for priming words.

\section{EXPERIMENT 1}

\section{Method}

Subjects. Fifty-six Wayne State University students participated in the experiment.

Stimulus materials. Twenty sets of five monosyllabic words were constructed, with each set containing a target word and four prime words. The prime words varied in their orthographic and phonological similarity to the target word. One prime in each set was (1) orthographically similar to the target word (e.g., bead-bread), (2) phonologically similar to the target word (e.g., bed-bread), and (3) orthographically and phonologically similar to the target word (e.g., dead-bread). The fourth type of prime was neither orthographically nor phonologically similar to the target word and served as a control condition. The full set of stimuli is presented in Appendix A.

Using the KuXera and Francis (1967) norms, word frequencies were matched as closely as possible within sets, given the constraints on set construction. Median word frequencies for the four types of prime were: orthographically similar, 70; phonologically similar, 12; orthographically and phonologically similar, 38 ; controls, 71 . The median frequency of the target words was 50 .

The 20 sets of four prime-target pairs were counterbalanced across four 20-trial blocks, with the restriction that each block contain only one prime-target pair from each set. Thus each prime word appeared in one block, whereas each target word appeared four times, once in each block. Each block contained five examples of each of the four types of prime-target pairs.

Four $2 \times 2$ in. slides were made of each target word using Letraset colored transparencies. The words were printed in lowercase letters. Equal numbers of target words were printed in each of four colors: blue, yellow, green, and red. Each target word appeared in only one color. Slides were also made of the primes in each presentation block. The words were typed in lowercase letters on acetate. The primes in each block were also recorded on one channel of stereo recording tape at a rate of approximately one word every 6 sec.
Procedure. Each subject was given 90 trials: 10 practice trials followed by the four 20-trial blocks. The blocks were counterbalanced across four orders in a modified Latin square. Each trial consisted of a prime word, presented either auditorily or visually, followed by the target word. Subjects were instructed to pay attention to the prime word and then to name the color that the target word was printed in as quickly as possible. Subjects were assigned to either the auditory or the visual presentation mode condition, with seven subjects within each presentation mode assigned to each of the four orders.

In both presentation modes, the target word appeared $200 \mathrm{msec}$ after the offset of the prime word. The target word was rear-projected on a screen, using a Kodak Carousel slide projector, when a shutter attached to a rotary motor opened. At a viewing distance of $54 \mathrm{~cm}$, the target words subtended a visual angle of about $5.6 \mathrm{deg}$ horizontally and $1.2 \mathrm{deg}$ vertically. The shutter closed when the subject named the color of the target word into a microphone connected to a second voice relay. The interval from the opening of the shutter until the subject's response was timed in milliseconds.

In the auditory presentation mode, subjects heard the prime words binaurally over stereo headphones. A timing tone (at the end of the prime word) that was inaudible to the subject activated a voice relay that initiated the timing of a $200-\mathrm{msec}$ interval. At the end of this interval, a relay contact closure opened the shutter, and the target word appeared.

In the visual condition, the prime was rear-projected for $300 \mathrm{msec}$ using a Carousel slide projector and a tachistoscopic shutter. An interval timer and relay were again used to program the 200-msec delay that intervened between the offset of the prime and the onset of the target word.

\section{Results}

Of the 4,480 possible color naming latencies, 271 $(6.4 \%)$ were not included in the analysis. Two hundred and eleven of these times were lost either because the subject did not speak loudly enough to trip the voice relay or because of equipment malfunctions. The remaining 61 scores $(1.3 \%)$ were errors in which the subject either named the word or the wrong color. Missing scores were randomly distributed across experimental conditions and were not replaced in the analyses.

Mean latencies for each subject were computed by collapsing across the 20 exemplars in each of the four prime conditions. In addition, overall item means were computed for each target word preceded by the four types of primes by collapsing across all 28 subjects in the auditory and visual prime conditions, respectively.

Overall mean latencies for each prime condition for both auditory and visual presentation modes are presented in Table 1. Color naming latencies were faster overall in the visual condition than in the auditory condition. For both presentation modes, color naming latencies were longer when the target was preceded by a phonologically and/or orthographically similar prime than when preceded by a control prime. Thus, priming occurred along both orthographic and phonological dimensions for both presentation modes. However, the rank order of the latencies for the three types of related primes differed in the auditory and visual conditions. The most prominent difference was that, in the auditory condition, the longest latencies followed primes that were both orthographically and phonologically related 
Table 1

Color Naming Latencies (L) in Milliseconds to Target Words

\begin{tabular}{lccccc} 
& \multicolumn{2}{c}{ Auditory Primes } & & \multicolumn{2}{c}{ Visual Primes } \\
\cline { 2 - 3 } \cline { 5 - 6 } Relationship of Prime and Target & L & ER & & L & ER \\
\hline Phonologically Similar & 776 & 1.1 & 744 & 1.3 \\
Orthographically Similar & 764 & 1.1 & 746 & 1.4 \\
Phonologically and Orthographically Similar & 781 & 1.4 & 742 & 1.4 \\
Unrelated & 740 & 1.4 & 719 & 1.4 \\
\hline
\end{tabular}

Note $-E R=$ error rate (in percentages).

to the target, whereas with visual presentation, this condition had the shortest (by $4 \mathrm{msec}$ ) latencies.

Analyses were performed on both subject and item means for reasons outlined by Clark (1973). ${ }^{2}$ A combined ANOVA on the auditory and visual presentation conditions revealed an effect of prime type in the subject analysis $[\mathrm{F}(3,81)=15.23, \mathrm{MSe}=821.5, \mathrm{p}<.001]$ and in the item analysis $[F(3,57)=6.48, \mathrm{MSe}=1,358.0$, $\mathrm{p}<.001]$. There was a large effect of presentation mode in the item analysis $[\mathrm{F}(1,57)=17.37, \mathrm{MSe}=1,597.1$, $\mathrm{p}<.001]$, but not in the subject analysis $[\mathrm{F}(1,81)=1.41$, MSe $=30,046.9]$. This discrepancy was due to the fact that items and presentation mode were crossed, whereas subjects and presentation mode were nested. The Presentation Mode by Prime Type interaction did not approach significance in either the subject analysis $[\mathrm{F}(3,81)=1.60, \mathrm{MSe}=849.3]$ or the item analysis $[F(3,57)=1.29, \mathrm{MSe}=1,018.1]$. No other effects or interactions approached significance.

Separate ANOVAs were also performed on the auditory and visual conditions. For the auditory condition, there was an effect of prime type in the subject analysis $[\mathrm{F}(3,81)=8.72, \mathrm{MSe}=1,074, \mathrm{p}<.001]$ and in the item analysis $[\mathrm{F}(3,57)=4.62$, MSe $=1,552.6$, $\mathrm{p}<.01]$. For the visual condition, there was also an effect of prime type in the subject analysis $[F(3,81)=$ $7.04, \mathrm{MSe}=639.9, \mathrm{p}<.001]$ and in the item analysis $[F(3,57)=3.58, \quad M S e=823.5, p<.05]$. No order effects or interactions obtained in any of these analyses.

For both the auditory and visual conditions, Dunnett comparisons were performed on the subject and item analyses in order to determine whether or not each of the related prime types differed from the control (Winer, 1971, pp. 201-204). All comparisons were significant at the $\alpha=.01$ level (one-sided confidence intervals), with the exception of the orthographically similar primes in the item analysis of the auditory condition. NewmanKeuls comparisons indicated that none of the three related primes differed significantly from each other in either the visual condition or the auditory condition, whereas all three related primes differed from the unrelated control.

The difference in word frequency among the prime conditions raises the possibility that some of the results might be attributable to this variable. In order to evaluate this possibility, correlations between word frequency and naming latency were computed for each prime type and for all of the prime types combined, in both the auditory and visual conditions. All of these correlations were positive; however, none approached significance. Since control primes had the highest word frequency, any frequency effects would have tended to increase the naming latencies following control primes relative to related primes. Thus it seems highly unlikely that the results are compromised by word frequency differences among the prime types.

\section{Discussion}

Both auditory and visual primes increased color naming interference to orthographically and/or phonologically similar target words. Thus the results seem to clearly support the multiple-code activation hypothesis. There is, however, a possible artifact in Experiment 1 and in C. Conrad's (1978) experiment that compromises the conclusion that orthographic codes are activated in auditory word recognition. In both of these studies, orthographically related prime-target pairs such as "touch-couch" were compared with unrelated controls such as "floor-couch." Longer color naming latencies to "couch" preceded by "touch" compared with "floor" were taken as evidence of orthographic priming. However, in these stimuli, the orthographic primes usually share more phonemes with the target word than do the unrelated primes. In Experiment 1, all but one of the orthographically related primes shared at least one phoneme with the target, whereas only three unrelated primes shared one or more phonemes with the target. It is possible, then, that the color naming interference in the orthographic condition is due to phonological priming. On this interpretation, the four types of primes in the auditory condition represent a continuum of phonological similarity with their respective targets. Unrelated primes have the least similarity (e.g., skillbread), with phonologically similar and both orthographically and phonologically similar primes having the greatest amount of similarity (e.g., bed-bread and dead-bread, respectively). Orthographically similar targets (e.g., bead-bread) have an intermediate amount of similarity. If priming was simply occurring along the phonological dimension with the magnitude of priming determined by phonological similarity, then the following order of color naming latencies would be predicted: 
unrelated $<$ orthographic $<$ phonological $=$ phonological and orthographic. If, however, the priming in the orthographic condition was actually due to orthographic similarity, then more priming should obtain in the both orthographically and phonetically similar condition than in the phonetically similar condition. Unfortunately, however, the order of means does not unambiguously support either interpretation. Furthermore, the means in the related conditions did not differ statistically.

There is, however, a control condition that can be used to determine whether there was true orthographic priming in the auditory condition. Instead of using unrelated words as control primes, phonological controls that rhyme with the orthographic primes can be used. An example of a phonological control for the pair "touch-couch" would be "dutch-couch." "Dutch" and "touch" share the same number of phonemes with the target "couch"; however, "touch" is more similar orthographically. Experiment 2 used the color naming paradigm to compare targets preceded by orthographic, unrelated, and phonologically matched controls. If the color naming interference in the orthographic condition in Experiment 1 was due to phonological similarity, then an equal amount of color naming interference should obtain in both the orthographic and phonological control conditions compared with the unrelated condition. If, however, there was true orthographic priming, then more color naming interference should obtain in the orthographic condition than in the phonological control condition.

\section{EXPERIMENT 2}

\section{Method}

Subjects. Twenty-four Wayne State University students participated in the experiment.

Stimulus materials. Eighteen stimulus sets were constructed, with each set containing a target word and three pairs of related primes. Pairs of prime words were used because subjects in Experiment 1 reported occasional difficulty in understanding a few of the spoken prime words, and using pairs of words increased the intelligibility of the primes. The words in each prime pair rhymed. Orthographic primes were spelled similarly to the target word, although they were pronounced differently (e.g., light, sight-eight). Phonological control primes rhymed with the orthographic primes, but they were spelled differently from their targets (e.g., bite, kite-eight). The unrelated primes were phonologically and orthographically dissimilar to the target word (e.g., moon, soon-eight). The full set of stimuli is presented in Appendix B.

The 18 sets of prime target pairs were balanced across three blocks, with the restriction that each block contain only one prime-target pair taken from each set. Thus each prime pair appeared in only one block, whereas each target word appeared three times, once in each block. Each block contained six exemplars of each condition. Order within block was randomized, except for the following three constraints: (1) The same colored target could not appear on successive trials, (2) prime target pairs from the same condition could not appear on successive trials, and (3) the first trial in each block was a filler trial.

Three $2 \times 2$ in. slides were made of each target word, using Letraset colored transparencies. The words were printed in uppercase letters. Equal numbers of target words were printed in each of three colors: red, yellow, and green. Each target word always appeared in only one color across blocks. Eighteen filler trials in which the primes and targets were unrelated were also included. The target words in these filler trials were printed in blue. The filler trials were included to add a fourth color, because the magnitude of color naming effects increases with the number of colors used.

The prime pairs were recorded on one channel of a stereo tape. The prime words on each trial were separated by about $1 \mathrm{sec}$. The rate of presentation was approximately one trial every $5 \mathrm{sec}$.

Procedure. Each subject was presented with 82 trials: 10 practice trials followed by three 24-trial blocks. The order of block presentation was counterbalanced across three orders in a modified Latin square. Each trial contained a trial number followed by the prime words. The target word was rear-projected $200 \mathrm{msec}$ after the end of the second prime word. Subjects were instructed to attend to the prime words and then to name the color that the target word was printed in as rapidly as possible. The other details of the procedure were identical to Experiment 1.

\section{Results and Discussion}

Of the 1,296 possible color naming latencies, 52 (4.3\%) were not included in the analysis. Twenty-six scores were lost either because the subjects did not speak loudly enough to trip the voice relay or because of equipment malfunctions, and 12 were lost because of experimenter error. The remaining 15 scores were errors in which the subject either named the word or the wrong color.

Mean latencies for each subject were computed by collapsing across the 18 exemplars in each of the three prime conditions. Item means were computed for each target word when preceded by the three prime conditions by collapsing across the 24 subjects. Overall mean latencies and error rates for each prime condition are presented in Table 2. Color naming latencies were longest in the orthographic prime condition $(763 \mathrm{msec})$, followed by the phonetic control condition $(732 \mathrm{msec})$ and the unrelated control condition $(719 \mathrm{msec})$. ANOVAs performed on both the subject and item means demonstrated effects of prime type $[F(2,46)=$ $5.60, \mathrm{MSe}=1,961.3, \mathrm{p}<.01$, in the subject analysis, and $F(2,34)=8.88, \mathrm{MSe}=1,029.8, p<.001$, in the item analysis].

Newman-Keuls comparisons among the three condition means revealed that color naming times in the orthographic prime condition were significantly longer than in the unrelated condition $[Q(2,46)=4.67, \mathrm{p}<.01$, in the subject analysis, and $\mathrm{Q}(2,34=5.82, \mathrm{p}<.01$, in the item analysis]. The means in the phonological control

Table 2

Color Naming Latency (L) in Milliseconds for Experiment 2

\begin{tabular}{llrr}
\multicolumn{1}{c}{ Prime Condition } & & L & ER \\
\hline Orthographic & LIGHT, FIGHT-EIGHT & 763 & .9 \\
Phonological Control & BITE, KITE-EIGHT & 732 & 1.4 \\
Unrelated Control & MOON, SOON-EIGHT & 719 & 1.1 \\
\hline
\end{tabular}

Note-ER = error rate (in percentages). 
and unrelated conditions did not differ significantly in either the subject analysis $[Q(2,43)=1.78, p<.25]$ or the item analysis $[\mathrm{Q}(2,34)=1.72, \mathrm{p}<.25]$. The critical comparison involves the orthographic and the phonological control conditions. Newman-Keuls comparisons indicated that the orthographic condition differed significantly from the phonological control condition in both the subject analysis $[\mathrm{Q}(2,46)=2.92, \mathrm{p}<.05]$ and the item analysis $[Q(2,34)=4.10, \mathrm{p}<.01]$.

In order to determine whether the results might reflect strategies resulting from repeated targets, separate means for each subject were calculated for each presentation block. Blocks were arranged in the order in which they were presented (first, second, or third) for each subject, and an analysis was conducted with block order as a factor. If strategies were developing during the course of the experiment, then they should be reflected in a Block Order by Prime Type interaction. This interaction did not approach significance $[F(4,92)<1]$.

Since the orthographic condition differed significantly from the phonological control condition, Experiment 2 provides clear evidence that encoding a spoken word results in the priming of orthographically similar words. The difference between the orthographic and phonological control conditions is particularly impressive given the constraints on the stimuli. In the phonological control and orthographic conditions, the primes and targets are matched for phonological similarity. One consequence of this matching is that the primes and targets in the phonological control condition are orthographically somewhat similar. Thus the phonological control condition minimizes the extent to which controls and orthographic primes can differ along the orthographic dimension.

Experiment 2 does not provide definitive evidence indicating whether or not some phonological priming occurred in the orthographic condition in Experiment 1. While the phonological and unrelated control conditions did not differ statistically, color naming latencies were $13 \mathrm{msec}$ longer in the phonological control condition. This difference could be due to phonological similarity or orthographic similarity, since there was some overlap between the primes and targets along both dimensions in the phonetic control condition. The small difference between phonetic and unrelated controls raises a problem in selecting control conditions for experiments investigating orthographic similarity. Using unrelated words as control primes maximizes the difference in orthographic similarity between conditions at the risk of confounding phonological similarity, whereas using rhyme controls eliminates the possible phonological confound but minimizes the extent to which conditions can differ along the orthographic dimension of interest.

\section{GENERAL DISCUSSION}

The present experiments demonstrated that color naming interference obtained when target words were preceded by words with similar phonological or orthographic information. The same results obtained whether the prime word was presented auditorily or visually. Cross-modal code activation was observed: With visual primes and targets, shared phonological information produced color naming interference; with auditory primes and visual targets, shared orthographic information produced color naming interference. The orthographic effects with auditory primes replicate C. Conrad's (1978) work and demonstrate that access of the orthographic code in auditory word recognition is not limited to the rhyme-monitor task used by Seidenberg and Tanenhaus (1979).

These results indicated that both orthographic and phonological codes become available in both auditory and visual word recognition. The fact that subjects accessed multiple codes even though the codes had a negative effect on performance of the experimental task suggests that these codes did not become available because of a conscious strategy. Rather, it appears that multiple codes are accessed automatically as a consequence of word recognition. If this interpretation is correct, it suggests reinterpretation of classic "recoding" effects in visual word and letter recognition. Both short-term memory tasks and immediate recognition tasks with visual stimuli show evidence of sound-based confusions, whereas auditory stimuli rarely show evidence of visually based confusions. In models of memory such as Atkinson and Shiffrin (1968), these results are accounted for by assuming that visually presented linguistic information is recoded into a sound-based code some time after initial encoding. The present results suggest that this code becomes available not as a function of a temporally distinct recoding stage, but rather as an automatic consequence of initial encoding. On this view, both phonological and orthographic codes for words become available, regardless of presentation modality. A code will rapidly decay, however, unless it is selected for maintenance in working memory. Since auditory rehearsal is probably more efficient than visual rehearsal for linguistic material, orthographic information will usually be available only briefly.

There is one result in the literature that appears to challenge the view that the phonological code develops automatically during visual word recognition. Meyer et al. (1974) demonstrated that lexical decision times to orthographically similar but phonologically dissimilar pairs such as "freak-break" showed interference relative to unrelated word pairs. They argued that this result obtained because subjects were accessing the lexicon through a phonological code. Shulman et al. (1978), however, replicated Meyer et al. (1974) only when the nonword pairs were pronounceable. With nonpronounceable nonwords, "freak-break" pairs showed facilitation. Shulman et al. argued that accessing the lexicon through a phonological code is an optional strategy that subjects develop because of the difficulty of the lexical decision in discriminating pronounceable nonwords from real words. 
The conflict between our results and those of Shulman et al. (1978) may, however, be more apparent than real. It is likely that the type of nonword used in a lexical decision task influences the information used by the subject in making lexical decisions. However, it may not influence which codes develop during the initial processing of words. On this view, the differential patterns obtained to "freak-break" pairs with different types of nonwords may be due to a decision strategy adopted by the subject in making lexical decisions, rather than to a strategy that determines which codes for a word are initially accessed. The results of recent studies by Collings (1980) and Seidenberg \& Dosher (Note 1) are consistent with this interpretation.

A further question concerns the mechanism by which prime words affected the encoding of the targets. One possibility is to interpret orthographic and phonological priming effects in the same way as semantic priming as due to spreading activation along a network in memory organized in terms of semantic similarity. When a word is recognized, a location in the network is activated, and activation subsequently spreads the nodes of related words. Thus, when one of these words is presented as a target, it is recognized faster than an unrelated word. It could similarly be argued that word recognition produces spreading activation along phonological and orthographic networks. While this model would account for orthographic and phonological priming effects, there does not seem to be any functional reason for networks organized along the dimension of orthographic and/or phonological similarity. Natural language processing might be facilitated by activation of a network of semantically related words, but not by activation of orthographic and/or phonological words.

A second possibility is that the priming effects are sublexical, that is, due to processes involved in the initial sensory analysis of the prime word. The initial decoding of the prime proceeds with some type of feature analysis; when a feature is recognized, a feature count is incremented at the logogens for all words containing that feature. If a target word sharing features with the prime is subsequently presented, it will be recognized more rapidly than an unrelated word, resulting in color naming interference to the target. Thus, with visual presentation, the sensory analysis of the priming word "flown" will result in lowered detection thresholds for any words sharing its visual features (clown, blown). Similarly, with auditory presentation, words sharing its auditory features will be facilitated (stone, blown). The sublexical interpretation founders on two cases, however: phonologically similar pairs with entirely visual presentation (flown-stone) and orthographically similar pairs with auditory presentation (flown-clown). That is, with visual presentation, a word can prime phonologically similar words only if they also happen to be orthographically similar; with auditory presentation, a word can prime orthographically similar words only if they happen to be phonologically similar. If a word pair shares only phonological features (flownstone), it is difficult to see how the visual feature analysis of the prime could facilitate the target; if the pair shares orthographic features (flown-clown), phonological feature analysis of the prime cannot facilitate the target. These cases oblige us to consider another mechanism, while acknowledging that the sublexical interpretation is adequate for some cases.

A third possibility is that cross-modal priming occurs after lexical access, but not through spreading activation. On this view, a word is recognized through the code related to the modality in which the word is presented. Lexical access then makes available the alternate code for the word. In auditory word recognition, the orthographic code becomes available as a consequence of lexical access, and in visual word recognition, the phono. logical code becomes available as a consequence of lexical access. When a word sharing these features is presented, its sensory analysis proceeds more rapidly because these features have already been activated.

Postulating a postlexical explanation for cross-modal priming effects raises the possibility that within-modal priming effects may also be postlexical. It is also possible that both pre- and postlexical priming can occur when the prime and target words share a code related to the modality that the prime is presented in. These possibilities are highly speculative, of course, and future research will be necessary to more precisely identify the loci of within- and cross-modal priming effects.

\section{REFERENCE NOTE}

1. Seidenberg, M. S., \& Dosher, B. A. Time course of phonological code activation in visual word recognition. Paper presented at the 49th meeting of the Eastern Psychological Association, Philadelphia, April 1979.

\section{REFERENCES}

Atkinson, R. C., \& Shiffrin, R. M. Human memory: A proposed system and its control processes. In K. W. Spence \& J. T. Spence (Eds.), The psychology of learning and motivation (Vol. 2). New York: Academic Press, 1968.

BADDELEY, A. The influence of acoustic and semantic similarity in short term memory for word sequences. Quarterly Journal of Experimental Psychology, 1966, 18, 362-365.

Becker, C., \& Killion, T. Interaction of visual and cognitive effects in word recognition. Journal of Experimental Psychology: Human Perception and Performance, 1977, 3, 389-401.

CLARK, H. H. The language-as-fixed-effect fallacy: A critique of language statistics in psychological research. Journal of Verbal Learning and Verbal Behavior, 1973, 12, 335-359.

Collings, A. K. Time course of phonological, orthographic, and semantic code activation in visual word recornition. Unpublished master's thesis, Wayne State University, 1980.

Colians, A. M., \& Loftus, E. F. A spreading-activation theory of semantic processing. Psychological Review, 1975, 82, 407-428.

Conrad, C. Some factors involved in the recognition of words. In J. W. Cotton \& R. L. Klatzky (Eds.), Semantic factors in cognition. Hillsdale, N.J: Erlbaum, 1978.

ConRad, R. Acoustic confusions in immediate memory. British Journal of Psychology, 1964, 55, 75-84.

Fischler, I. Associative facilitation without expectancy in a lexical 
decision task. Journal of Experimental Psychology: Human Perception and Performance, 1977, 3, 18-26.

Kavanagh, J. F., \& Mattingly, I. G. (Eds.). Language by ear and by eye. Cambridge: M.I.T. Press, 1972.

KuČEra, H., \& Francis, W. N. Computational analysis of present-day American English. Providence, R.I: Brown University Press, 1967.

Meyer, D. E., \& Schvaneveldt, R. W. Meaning, memory structure, and mental processes. Science, 1976m 192, 27-33.

Meyer, D., Schvaneveldt, R., \& Ruddy, M. Functions of graphemic and phonemic codes in visual word recognition. Memory \& Cognition, 1974, 2, 309-321.

Meyer, D. E., Schvaneveldt, R. W., \& Ruddy, M. G. Loci of context effects in visual word recognition. In P. M. A. Rabbitt \& S. Dornic (Eds.), Attention and performance $V$. New York: Academic Press, 1975.

Monton, J. Interaction of information in word recognition. Psychological Review, 1969, 76, 163-178.

NEELY, J. H. Semantic priming and retrieval from lexical memory: Evidence for facilitatory and inhibitory processes. Memory \& Cognition, 1976, 4, 648-654

NeELY, J. H. Semantic priming and retrieval from lexical memory: Roles of inhibitionless spreading activation and limited-capacity attention. Journal of Experimental Psychology: General, 1977, 106, 226-254.

Posner, M., \& Snyder, C. Attention and cognitive control. In $\mathrm{R}$. Solso (Ed.), Information processing and cognition: The Loyola symposium. Hillsdale, N.J: Erlbaum, 1975.

Seidenberg, M. S., \& Tanenhaus, M. K. Orthographic effects on rhyme monitoring. Journal of Experimental Psychology: Human Learning and Memory, 1979, 5, 546-554.

Shulman, H. G., Hornak, R., \& Sanders, E. The effects of graphemic, phonetic, and semantic relationships on access to lexical structures. Memory \& Cognition, 1978, 6, 115-123.

WARREN, R. E. Stimulus encoding and memory. Journal of Experimental Psychology, 1972, 94, 90-100.

WARren, R. E. Association, directionality, and stimulus encoding. Journal of Experimental Psychology, 1974, 102, 151-158.

WICKELGREN, W. Acoustic similarity and intrusion errors in short-term memory. Journal of Experimental Psychology, 1965, 70, $102-108$

WINER, B. J. Statistical principles in experimental design. New York: McGraw-Hill, 1971.

\section{NOTES}

1. This work was begun independently, however, before we became aware of $C$. Conrad's work.

2. The population of words meeting the constraints for either Experiment 1 or Experiment 2 is extremely small. Thus, target words are more properly treated as a fixed factor than as a random factor. As a consequence, our stimuli do not meet the assumptions for either the $\mathrm{F} 2$ (by-item) or the $\min \mathrm{F}^{\prime}$ statistic, both of which assume that items are treated as a random factor. However, to obtain some estimate of whether or not the results obtained were consistent within our sample of items, we treated items as a random factor in order to obtain an error term for F2. As a consequence, the resulting item analyses are extremely conservative, because they overestimate the true error term.
Appendix A

Stimuli for Experiment 1

\begin{tabular}{lllll} 
& \multicolumn{2}{c}{ Primes } & & \\
\cline { 1 - 2 } $\mathrm{O}$ & $\mathrm{P}$ & $\mathrm{P}+\mathrm{O}$ & $\mathrm{U}$ & Targets \\
\hline good & rude & mood & well & food \\
done & blown & tone & host & bone \\
are & air & stare & miss & dare \\
plow & doe & flow & dream & slow \\
soot & cute & boot & brain & root \\
ward & guard & yard & bag & hard \\
bead & bed & dead & skill & bread \\
lower & hour & tower & game & power \\
how & go & low & take & row \\
shoe & grow & woe & short & foe \\
home & dumb & some & year & come \\
hood & bud & blood & lose & flood \\
foot & brute & boot & milk & hoot \\
cost & boast & host & thank & most \\
lose & toes & prose & had & nose \\
shall & crawl & call & left & hall \\
put & what & nut & less & but \\
choose & truce & loose & map & goose \\
bowl & towel & growl & bend & howl \\
cough & bluff & tough & put & rough \\
\hline
\end{tabular}

Note $-O=$ orthographically similar; $P=$ phonologically similar $U=$ unrelated.

Appendix B

Stimuli for Experiment 2

\begin{tabular}{llll}
\hline \multicolumn{1}{c}{ OS } & \multicolumn{1}{c}{ Primes } & & \\
\cline { 1 - 2 } Bone, Tone & \multicolumn{1}{c}{ PC } & \multicolumn{1}{c}{ U } & Targets \\
Blow, Slow & Blown, Flown & Harm, Farm & None \\
Come, Some & Foe, Hoe & Card, Yard & Plow \\
Bead, Lead & Wum, Rum & Fit, Pit & Home \\
Hood, Good & Should, Could & Slip, Clip & Dead \\
Treat, Wheat & Fleet, Sweet & Coin, Join & Mood \\
Plight, Fight & Bite, Kite & Stay, Pray & Eight \\
Host, Post & Coast, Boast & Feed, Deed & Lost \\
Gear, Fear & Cheer, Beer & Code, Mode & Wear \\
Please, Tease & Knees, Bees & Drug, Plug & Cease \\
Speak, Freak & Meek, Cheek & Hiteh, Ditch & Break \\
Paid, Raid & Wade, Fade & Pill, Fill & Said \\
Loose, Goose & Truce, Spruce & Jam, Ham & Choose \\
Tomb, Womb & Gloom, Room & Wise, Rise & Bomb \\
Hoot, Boot & Cute, Brute & Rain, Gain & Foot \\
Fool, Cool & Rule, Mule & Race, Pace & Wool \\
Tower, Power & Sour, Hour & Built, Guilt & Lower \\
Rough, Tough & Bluff, Cuff & Brick, Trick & Cough \\
\hline
\end{tabular}

Note $-O S=$ orthographically similar $; \quad P C=$ phonetic control, $U=$ unrelated.

(Received for publication September 6, 1979; revision accepted June 4, 1980.) 